\title{
Immunohistochemical Expression of HER2/NEU and CD10 in Urothelial Carcinoma of Urinary Bladder
}

\author{
MAHMOUD S. ABDELHALIM SALEM, M.Sc.; AHMED I. ELSAYED, Ph.D. and \\ EMADELDIN R. MATAR, M.D.
}

The Department of Pathology, Faculty of Medicine, Al-Azhar University

\begin{abstract}
Background: The major prognostic factors in carcinoma of the bladder are the depth of invasion into the bladder wall and the degree of differentiation of the tumor. However, there is no reliable parameter predicting the risk of recurrence or progression. Molecular markers are, therefore, required to estimate the individual prognosis of patients as well as for effective treatment.

Aim of Study: To evaluate HER2/Neu \& CD 10 immunohistochemical expression in urothelial carcinoma of the urinary bladder and to determine the correlation between immunohistochemical expression and histopathologic parameters including grade and stage, thus contributing as prognostic factors.

Material and Methods: HER2/Neu and CD 10 were assessed by immunohistochemistry in 50 specimens of urinary bladder urothelial carcinoma, collected from Al-Azhar Faculty of Medicine Hospital labs during the period from January 2019 to February 2020. Specimens were obtained by either transurethral resection (TUR) or radical cystectomy.

Results: There was a statistically significant difference in HER2/Neu and CD 10 expression in high grade urothelial carcinoma compared with low grade urothelial carcinoma, and in invasive urothelial carcinoma versus noninvasive urothelial carcinoma.

Conclusion: HER2/Neu and CD 10 immunohistochemical expression was directly related to grade and stage of urothelial carcinoma of the bladder and could be of valuable significance in the differentiation between high and low-grade urothelial carcinoma of the bladder.
\end{abstract}

Key Words: HER2/Neu and CD1O Expression - Urinary bladder urothelial carcinoma.

\section{Introduction}

URINARY bladder cancer is the ninth most common malignancy worldwide and the most common malignancy involving the urinary system [1], and the eighth leading cause of cancer death in men [2]. The most common type of bladder cancer is

Correspondence to: Dr. Mahmoud S. Abdelhalim Salem, E-Mail: mahmoud.salem711@gmail.com urothelial carcinoma, which accounts for about $90 \%$ and $80 \%$ of bladder cancers in industrialized countries and other parts of the world, respectively [3] . Different parameters determine the prognosis of bladder carcinoma, including stage, grade, patient's age, and lymph node status. Prolonged survival in most patients with superficial cancers is achieved by transurethral resection (TUR) with or without intravesical chemotherapy. Nonetheless, these patients still have a high risk of recurrence following initial resection [4]. Bladder cancer has several molecular alterations and complex biological pathways that regulate cellular processes, such as proliferation, differentiation, angiogenesis, metastasis and apoptosis. The discovery of new biological markers, may lead to the improvement of clinical prediction and the personalization of therapeutic approaches of bladder cancer patients with the purpose of reducing the risk of progression [5]

The human epidermal growth factor receptor2 (HER2/neu) is a glycoprotein with tyrosine kinase activity. It is encoded by c-erbB2 gene which is localized to chromosome 17q. Increased activity of this molecule by gene amplification or protein overexpression can occur in a variety of human carcinomas [6]. Cellular effects of HER2 / neusignalling include cell growth, survival and migration. Abnormal activation of HER2/neu has been proposed to lead to oncogenic transformation [7] Targeting of the HER $2 /$ neu gene product by the monoclonal antibody trastuzumab (Herceptin) has led to advances in the treatment of certain carcinomas, including breast carcinoma [8]. Urothelial carcinoma has been extensively examined for expression of HER2/neu. Although there is variability in the reported percentage of urothelial carcinomas that overexpress HER2/neu, the consensus resides in the $35-40 \%$ range [9]. Increased protein expression of HER2/neu seems to correlate with earlier tumor recurrence [10], worsened pathologic 
stage and decreased survival [11], although the prognostic role of HER2/neu has been controversial and may vary depending on associated chemotherapeutic regimens [12].

CD 10 is a cell surface zinc dependent metalloprotease that inactivates various bioactive neuropeptides [13]. In addition to its enzymatic function, CD 10 protein has a direct role in signal transduction pathways that regulate cell growth and apoptosis and because of its structural similarity to the matrix metalloproteases in the stroma, CD10 is also thought to affect invasion and metastatic potential of tumor cells by altering the cellular microenvironment [14]. This was initially discovered on the surface of acute lymphoblastic leukaemia cells, and considered to be a tumor-specific antigen [15] This marker has a neutral endopeptidase activity and is known to regulate biological activities of peptide substrates. There are recent evidence demonstrating a correlation between apoptosis and CD10 expression [16]

The aim of this study is to evaluate HER2/NEU \& CD 10 immunohistochemical expression in urothelial carcinoma of the urinary bladder and to determine the correlation between immunohistochemical expression and histopathologic parameters including grade and stage, thus contributing as prognostic factors.

\section{Material and Methods}

This work included 50 specimens of urinary bladder urothelial carcinoma, collected from AlAzhar Faculty of Medicine Hospital labs during the period from January 2019 to February 2020. Specimens were obtained by either transurethral resection (TUR) or radical cystectomy. All the specimens were formalin fixed, and paraffin embedded. For all specimens, clinical data were available including clinical history and sex and age of the patients. Four micron thick sections were cut from paraffin blocks of all cases and stained with hematoxylin and eosin (H\&E) for histological reevaluation. All cases were re-evaluated; graded and staged according to the classification of WHO 2016 and TNM staging systemrespectively [17]

For immunohistochemical study; unstained positively charged slides were prepared from each paraffin block for immunostaining with mouse monoclonal antibodies against: HER 2 and CD10 [Dako, U.S.A]. Immunohistochemical reactions were carried out using Labeled Streptavidin-Biotin2 System-Horseradish Peroxidase (LSAB2 SystemHRP) which is based on a modified labeled AvidinBiotin (LAB) technique in which a biotinylated secondary antibody forms a complex with peroxidase-conjugated streptavidin molecules. The entire antibody complex is made visible by addition of an appropriate substrate chromogen reagent, which is converted by the peroxidase label to browncolored precipitate at the site of antigen localization in tissue. The chromogen used is diaminobenzidine (DAB) produced by Dako (U.S.A). For positive control, sections from normal endometrium were stained for CD 10, while sections of invasive ductal breast carcinoma positive for HER2/neu were considered as positive control for HER2.

Evaluation of HER2/neu Expression: Only membranous staining was regarded as positive. The interpretation score was as follows: (0), no staining or membrane staining observed in less than $10 \%$ of tumor cells; $(1+)$, partial faint membrane staining in more than $10 \%$ of tumor cells; $(2+)$, circumferential weak to moderate staining observed in more than $10 \%$ of tumor cells; $(3+)$, circumferential strong membrane staining observed in more than $10 \%$ of tumor cells. Scores 0 and +1 were regarded as negative, while scores $2+$ and $3+$ were regarded as positive [18]

Evaluation of CD10 Expression: The cytoplasm and/or cell membrane staining was regarded as positive expression. The interpretation score was as follows: (0) or negative, $<5 \%$ of tumor cells were positive; $(1+), 5-50 \%$ of tumor cells were positive; $(2+),>50 \%$ of tumor cells were positive [19].

Statistical analysis: Results were statistically analyzed using Statistical Package for Social Sciences, SPSS for windows. Data analysis was done using Chi-square test for Tables with frequencies. $p$-value $<0.05$ is considered statistically significant.

\section{Results}

This study involved 50 specimens of urinary bladder urothelial carcinoma. The age range of the studied patients was 29-85 years, and mean age was $(59.74 \pm 10.99)$ years. Forty-three cases $(86 \%)$ were males, and seven cases (14\%) were females. Thirty-three cases $(66 \%)$ were diagnosed as invasive urothelial carcinoma (Fig. 1), and seventeen cases $(34 \%)$ were diagnosed as non-invasive urothelial carcinoma (Fig. 2). Twenty-six of cases (52\%) were low grade (Fig. 2) and twenty-four cases $(48 \%)$ were high grade (Fig. 1). Seven cases (14\%) showed associated bilharzial cystitis. Tissue specimens were obtained by TUR in 32 cases (64\%) and by radical cystectomy in 18 cases (36\%). All cases were studied for of HER2/Neu, and CD10 immunoexpression. 


\section{Immunohistochemical expression of HER2/Neu:}

Among the 50 cases of urothelial carcinoma, 22 cases (44\%) expressed positivity for HER2/Neu. There was a significant correlation between HER2/Neu expression and the grade of the tumor $(p=0.000)$; where among low grade tumors, it was expressed in $3 / 26(11.5 \%)$ cases showing score 2 expression (Fig. 4), but negative in 23/26 (88.5\%) cases (Fig. 3). In high grade urothelial carcinoma, it was positive in $19 / 24(79.2 \%)$ of cases, with 15 cases $(62.5 \%)$ showing score 3 expression (Figs. $5,6)$ (Table 1). As regard the stage, HER2/Neu was expressed in only 1 case out of 17 cases $(5.9 \%)$ of non-invasive urothelial carcinoma showing score 2 expression, while it was positive in $21 / 33$ cases $(63.6 \%)$ of invasive urothelial carcinoma with 15 cases (45.5\%) showing score 3 expression (Fig. 6) (Table 1), and there was a statistically significant difference between stages $(p=0.000)$.

In contrast, patient's age and sex and associated bilharzial cystitis did not show any significant relationship with the expression of HER2/Neu ( $p=$ $0.099,0.184,0.474$ respectively) (Table 2 ).

Table (1): Relationship of tumor grade and stage with HER2.

\begin{tabular}{cllll}
\hline & \multicolumn{3}{c}{ HER2 } & $\begin{array}{c}p \text { - } \\
\text { value }\end{array}$ \\
\cline { 2 - 4 } & Negative & Score 2 & Score 3 & \\
\hline Grade: & & & 0.000 \\
Low $(\mathrm{n}=26)$ & $23(88.5 \%)$ & $3(11.5 \%)$ & $0(0.0 \%)$ & \\
High $(\mathrm{n}=24)$ & $5(20.8)$ & $4(16.7 \%)$ & $15(62.5 \%)$ & \\
Stage: & & & & 0.000 \\
Ta $(\mathrm{n}=17)$ & $16(94.1 \%)$ & $1(5.9 \%)$ & $0(0.0 \%)$ & \\
T1 $(\mathrm{n}=11)$ & $8(72.7 \%)$ & $2(18.2 \%)$ & $1(9.1 \%)$ & \\
T2 $(\mathrm{n}=10)$ & $3(30 \%)$ & $3(30 \%)$ & $4(40 \%)$ & \\
T3 $(\mathrm{n}=10)$ & $1(10 \%)$ & $1(10 \%)$ & $8(80 \%)$ & \\
T4 $(\mathrm{n}=2)$ & $0(0.0 \%)$ & $0(0.0 \%)$ & $2(100 \%)$ & \\
\hline
\end{tabular}

Table (3): Relationship of tumor grade and stage with CD10.

\begin{tabular}{lllll}
\hline & \multicolumn{3}{c}{ CD10 } & $\begin{array}{c}p- \\
\text { value }\end{array}$ \\
\cline { 2 - 4 } & Negative & Score 1 & Score 2 & \\
\hline Grade: & & & & \\
$\quad$ Low (n=26) & $21(80.7 \%)$ & $4(15.4 \%)$ & $1(3.9 \%)$ & 0.000 \\
High (n=24) & $4(16.7 \%)$ & $7(29.1 \%)$ & $13(54.2 \%)$ & \\
Stage: & & & & \\
Ta (n=17) & $15(88.2 \%)$ & $2(11.8 \%)$ & $0(0.0 \%)$ & 0.000 \\
T1 $(\mathrm{n}=11)$ & $7(63.6 \%)$ & $2(18.2 \%)$ & $2(18.2 \%)$ & \\
T2 $(\mathrm{n}=10)$ & $3(30 \%)$ & $2(20 \%)$ & $5(50 \%)$ & \\
T3 $(\mathrm{n}=10)$ & $0(0.0 \%)$ & $3(30 \%)$ & $7(70 \%)$ & \\
T4 $(\mathrm{n}=2)$ & $0(0.0 \%)$ & $1(50 \%)$ & $1(50 \%)$ & \\
\hline
\end{tabular}

\section{Immunohistochemical expression of CD10:}

Among the 50 cases of urothelial carcinoma, 25 cases (50\%) expressed positivity for CD10. There was a significant correlation between CD 10 expression and the grade of the tumor $(p=0.000)$; where among low grade tumors, it was expressed in $5 / 26(19.2 \%)$ cases, with one case only $(3.8 \%)$ showing score 2 expression (Fig. 8), and it was negative in $21 / 26(80.7 \%$ ) cases (Fig. 7). In high grade urothelial carcinoma, it was positive in 20/24 $(83.3 \%)$ of cases, with 13 cases $(54.1 \%)$ showing score 2 expression (Figs. 9,10) (Table 3). As regard the stage, CD10 was negative in $15 / 17$ cases $(88.2 \%)$ of non-invasive urothelial carcinoma, while it was positive in $23 / 33$ cases $(69.7 \%$ ) of invasive urothelial carcinoma with 15 cases $(45.5 \%)$ showing score 2 expression (Fig. 10), and there was a statistically significant difference between stages $(p=0.000)$ (Table 3$)$.

In contrast, patient's age and sex and associated bilharzial cystitis did not show any significant relationship with the expression of CD10 ( $p=0.282$, $0.623,0.461$ respectively) (Table 4 ).

Table (2): Relationship of patient's age and gender and bilharzial cystitis with HER2.

\begin{tabular}{|c|c|c|c|c|}
\hline & \multicolumn{3}{|c|}{ HER2 } & \multirow{2}{*}{$\begin{array}{c}p- \\
\text { value }\end{array}$} \\
\hline & Negative & Score 2 & Score 3 & \\
\hline \multicolumn{5}{|l|}{ Age: } \\
\hline Mean \pm SD & $61.79 \pm 10.1$ & $62.43 \pm 11.87$ & $54.67 \pm 11.24$ & 0.099 \\
\hline Range & $43-85$ & $50-80$ & $29-78$ & \\
\hline \multicolumn{5}{|l|}{ Gender: } \\
\hline Female $(n=7)$ & $3(42.9 \%)$ & $0(0.0 \%)$ & $4(57.1 \%)$ & 0.184 \\
\hline Male $(n=43)$ & $25(58.1 \%)$ & $7(16.3 \%)$ & $11(25.6 \%)$ & \\
\hline \multicolumn{5}{|l|}{ Bilharzial cystitis: } \\
\hline Absent $(n=43)$ & $25(58.1 \%)$ & $5(11.7 \%)$ & $13(30.2 \%)$ & 0.474 \\
\hline Present $(n=7)$ & $3(42.9 \%)$ & $2(28.55 \%)$ & $2(28.55 \%)$ & \\
\hline
\end{tabular}

Table (4): Relationship of patient's age and gender and bilharzial cystitis with CD 10.

\begin{tabular}{|c|c|c|c|c|}
\hline & \multicolumn{3}{|c|}{ CD10 } & \multirow{2}{*}{$\begin{array}{c}p- \\
\text { value }\end{array}$} \\
\hline & Negative & Score 1 & Score 2 & \\
\hline \multicolumn{5}{|l|}{ Age: } \\
\hline Mean \pm SD & $62.16 \pm 10.11$ & $58.27 \pm 10.46$ & $56.57 \pm 12.6$ & 0.282 \\
\hline Range & $43-85$ & $45-78$ & $29-80$ & \\
\hline \multicolumn{5}{|l|}{ Gender: } \\
\hline Female $(n=7)$ & $3(42.85 \%)$ & $1(14.3 \%)$ & $3(42.85 \%)$ & 0.623 \\
\hline Male $(n=43)$ & $22(51.2 \%)$ & $10(23.2 \%)$ & $11(25.6 \%)$ & \\
\hline \multicolumn{5}{|l|}{ Bilharzial cystitis: } \\
\hline Absent $(n=43)$ & $23(53.5 \%)$ & $9(20.9 \%)$ & $11(25.6 \%)$ & 0.461 \\
\hline Present $(n=7)$ & $2(28.6 \%)$ & $2(28.6 \%)$ & $3(42.8 \%)$ & \\
\hline
\end{tabular}




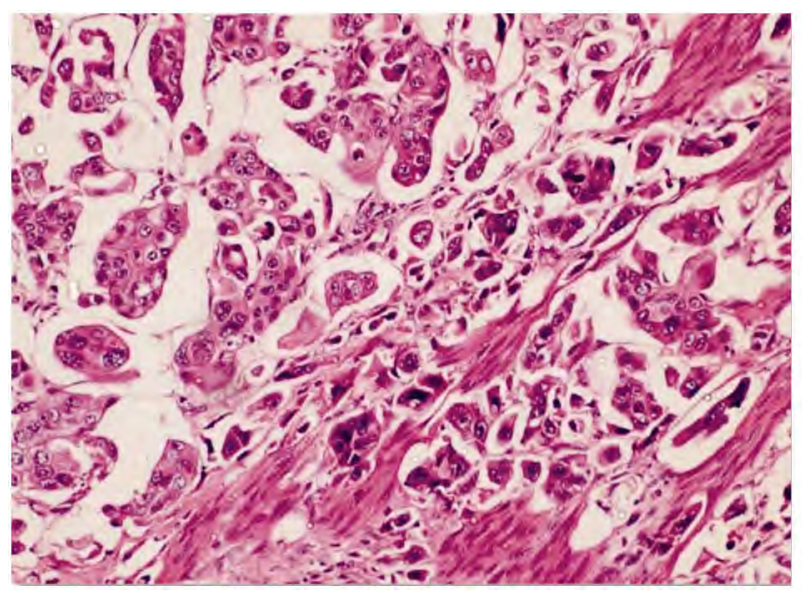

Fig. (1): High grade invasive urothelial carcinoma, showing clusters of markedly anaplastic urothelial cells infiltrating the muscle. $\mathrm{H} \& \mathrm{E}$ (x200).

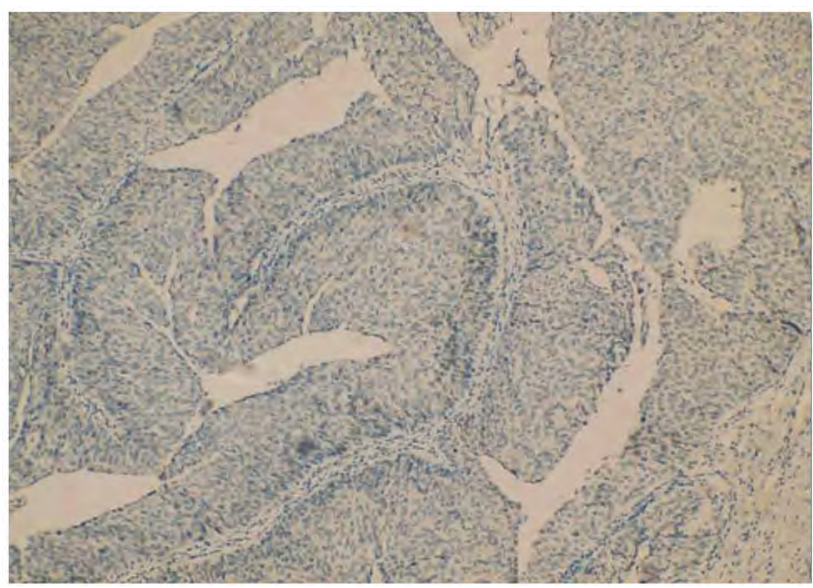

Fig. (3): Negative HER2 staining in low grade non-invasive urothelial carcinoma. (x100).

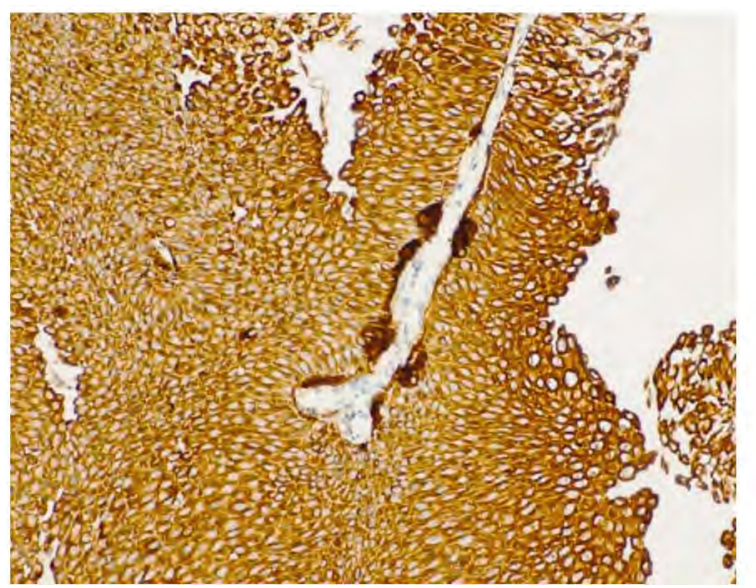

Fig. (5): HER2 expression in high grade urothelial carcinoma, score (3). There is circumferential strong membrane staining of more than $10 \%$ of tumor cells (x200).

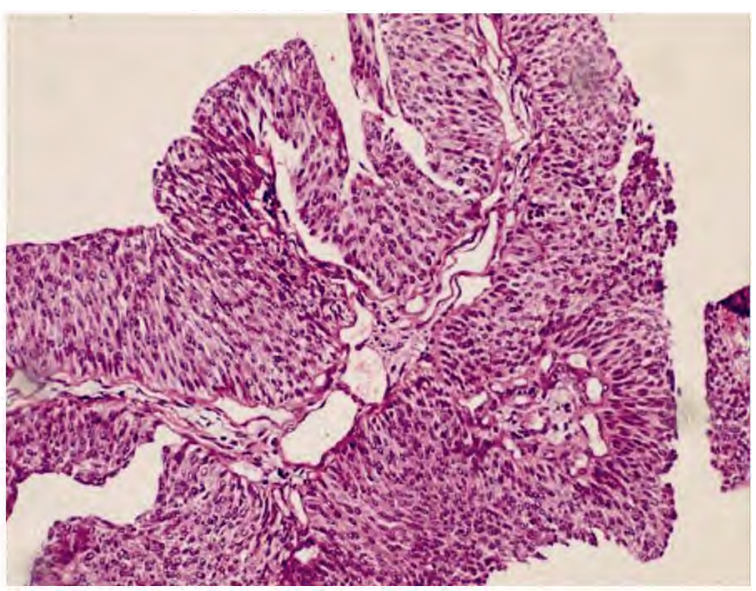

Fig. (2): Low grade non-invasive urothelial carcinoma, showing branching papillary fronds with variations in architectural and cytologic features. H\&E (x200).

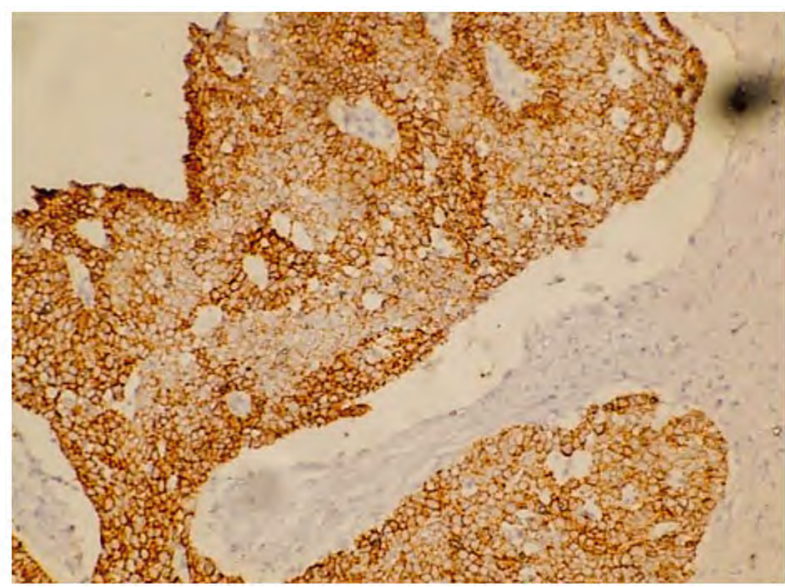

Fig. (4): HER2 expression in low grade urothelial carcinoma score (2). There is circumferential weak to moderate staining of more than $10 \%$ of tumor cells. (x200).

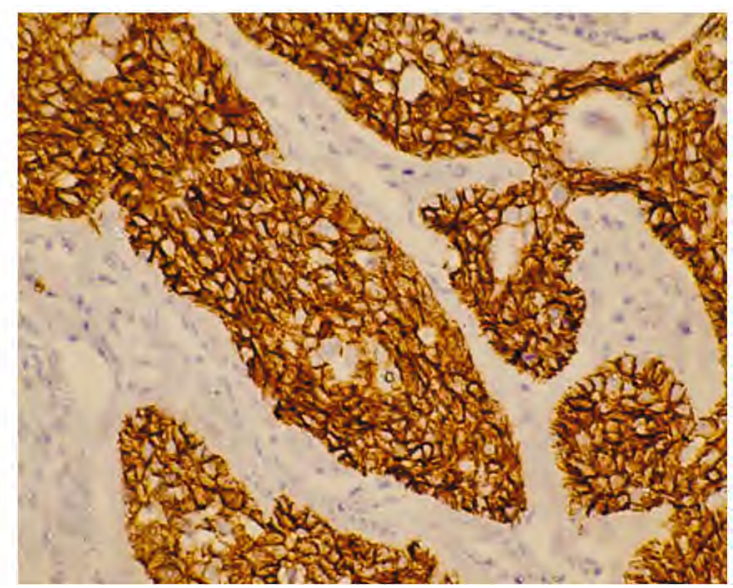

Fig. (6): HER2 expression in high grade invasive urothelial carcinoma, score (3). There is circumferential strong membrane staining of more than $10 \%$ of tumor cells (x400). 


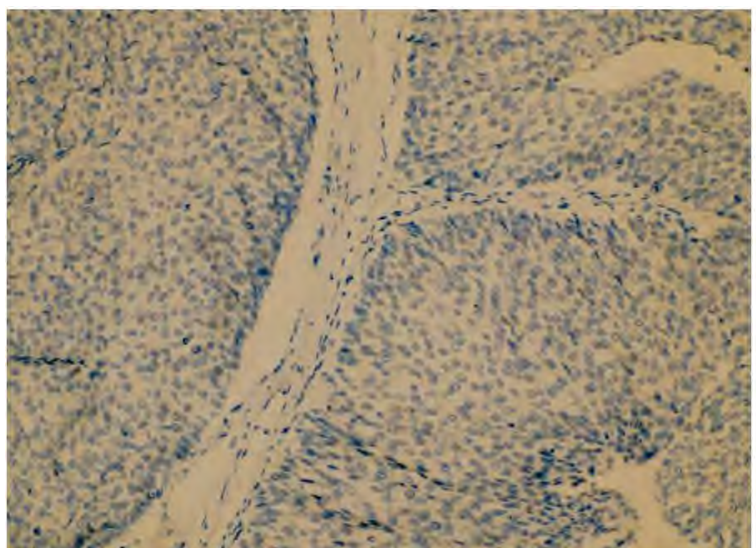

Fig. (7): Negative CD10 staining in low grade non-invasive urothelial carcinoma. (x200).

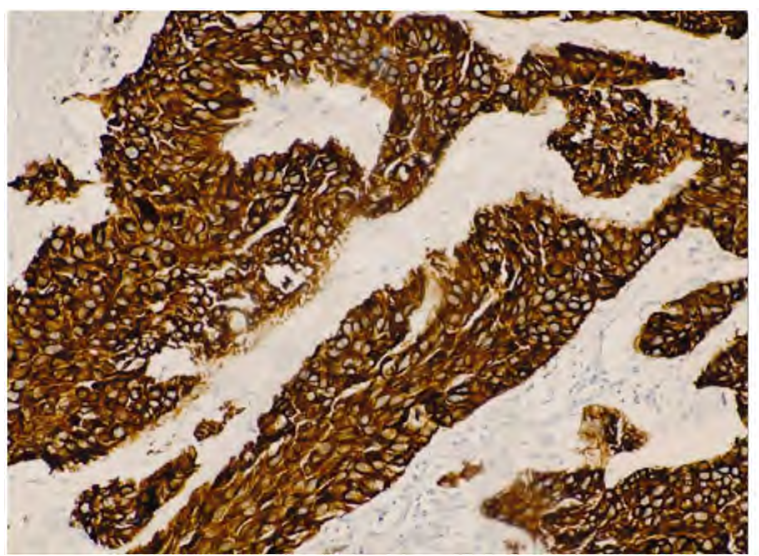

Fig. (9): CD10 expression in high grade urothelial carcinoma, score (2). More than $50 \%$ of tumor cells were positive. (x200).

\section{Discussion}

In the current study, 50 cases of urinary bladder urothelial carcinoma were studied, including 33 invasive urothelial carcinomas versus 17 noninvasive urothelial carcinomas, and 26 low grade urothelial carcinomas versus 24 high grade urothelial carcinomas.

The age of the patients ranged from 29 to 85 years, and mean age was $(59.74 \pm 10.99)$. Fortythree cases $(86 \%)$ were males, and seven cases $(14 \%)$ were females, with an average male to female ratio of (6.14:1). These results agree with those mentioned by Bahadir et al., [13].

In our study, we address HER2/Neu and CD10 as important players in urothelial carcinoma progression. The present research illustrates the expression of these markers in urothelial carcinoma, followed by illustrating the association between their immunohistochemical expression and clinicopathological parameters.

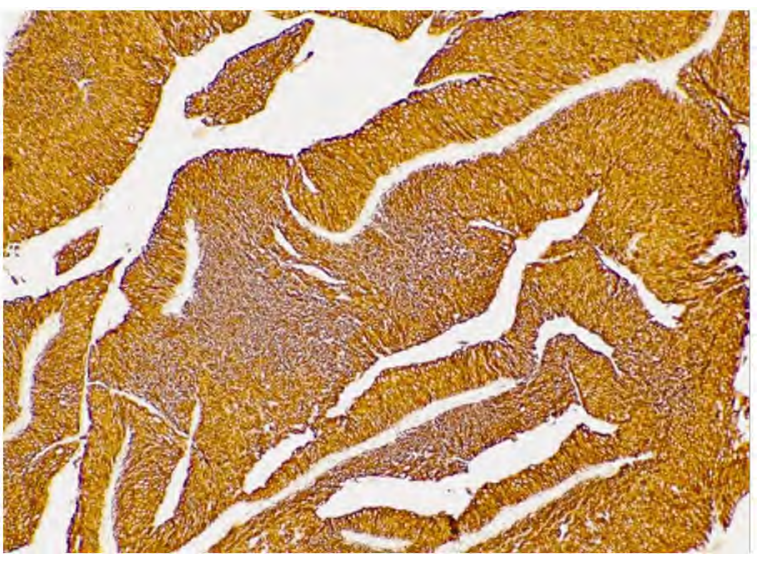

Fig. (8): CD10 expression in low grade urothelial carcinoma, score (2). More than $50 \%$ of tumor cells were positive. (x100).

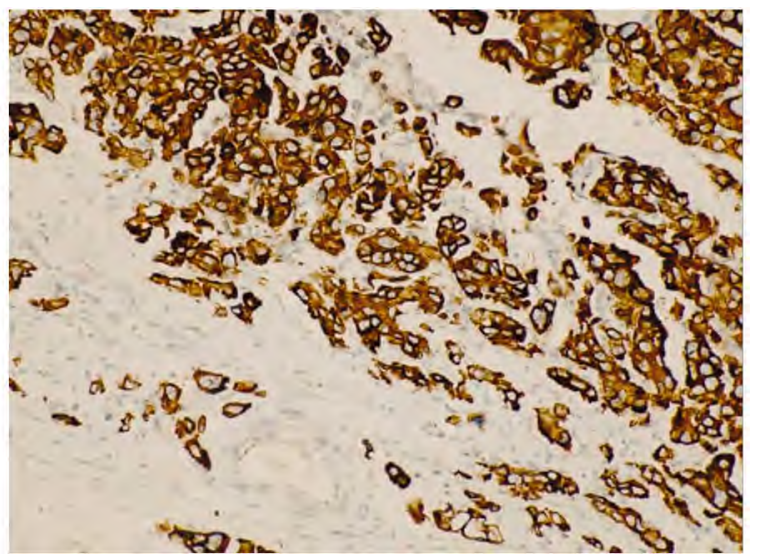

Fig. (10): CD10 expression in high grade invasive urothelial carcinoma, score (2). More than $50 \%$ of tumor cells were positive. $(\mathrm{x} 200)$.

In this study we found a statistically significant difference in HER2/Neu and CD10 expression in high grade urothelial carcinoma compared with low grade urothelial carcinoma, and in invasive urothelial carcinoma versus noninvasive urothelial carcinoma.

The current study showed that 23 out of 26 cases $(88.5 \%)$ of low grade urothelial carcinoma were HER2 negative, and 3 out of 26 cases (11.5\%) showed score 2 expression. In high grade urothelial carcinoma, HER2 was positive in 19/24 (79.2\%) of cases, with 15 cases $(62.5 \%)$ showing score 3 expression, and 5/24 (20.8\%) of cases were HER2 negative. As regard the stage, HER2/Neu was expressed in only 1 case out of 17 cases $(5.9 \%)$ of non-invasive urothelial carcinoma showing score 2 expression, while it was positive in $21 / 33$ cases $(63.6 \%)$ of invasive urothelial carcinoma with 15 cases $(45.5 \%)$ showing score 3 expression.

Our findings are similar to the reports of Jimenez et al., [20], Gandour-Edwards et al., [12], Coogan 
et al., [21], Kruger et al., [10], Atis et al., [22], Skagias et al., [23], Enache et al., [24], Shawky et al., [18], and Abd El-Fattah et al., [25] who found a statistically significant difference in HER2 protein expression in high grade urothelial carcinoma compared with low grade and in invasive urothelial carcinoma versus noninvasive urothelial carcinoma, with overexpression detected only in the high grade and invasive tumors. Although numerous researches have detected a negative prognostic significance and an aggressive role of HER2/Neu expression in urothelial carcinoma, others have not found any poor prognostic association [26]

Opposite of our results; Ioachim et al., [27] found no relation between HER2/Neu overexpression and the grade and stage of urothelial carcinoma, while Korkolopoulou et al., [28] and Vollmer et al., [29] linked Her-2 expression in bladder carcinoma with a better clinical outcome. Also, Alexa et al., [26] reported that HER2/Neu overexpression was not correlated with the tumor stage or lymph node status, but was significantly correlated with the differentiation grade. This difference may be due to the heterogeneity between antibodies, protocols and interpretations of HER2/Neu expression.

In agreement with El Gehani et al. [30] and Shawky et al., [18] , HER2 did not show any association with patient gender or age. As regard bilharzial cystitis our results are similar to those of Eissa et al., [31] and Shawky et al., [18] who found no significant difference in HER2 expression between the bilharzial and non bilharzial cancer groups.

As regard CD10 expression, the current study showed that it was expressed in 5/26 (19.2\%) cases of low grade urothelial carcinoma, with one case only (3.8\%) showing score 2 expression, and it was negative in $21 / 26(80.7 \%)$ cases. In high grade urothelial carcinoma, it was positive in $20 / 24$ (83.3\%) of cases, with 13 cases $(54.1 \%)$ showing score 2 expression. As regard the stage, CD 10 was expressed in 2 cases out of 17 cases $(11.8 \%)$ of non-invasive urothelial carcinoma showing score 1 expression, while it was positive in $23 / 33$ cases $(69.7 \%)$ of invasive urothelial carcinoma with 15 cases $(45.5 \%)$ showing score 2 expression. Thus, there was a strong correlation not only with histologic grade but also with pathologic stage.Similar results were obtained by Bahadir et al., [13], Kandemir et al., [32] and Mohammad et al., [33], and disagreed with other studies were done by Koiso et al., [34] and Bircan et al., [35].
Koiso et al., [34] were among the pioneers who studied CD 10 expression in bladder. They found that both enzyme activity and IHC expression were higher in superficial cancers than invasive cancers and normal urothelium. They concluded that CD 10 was expressed at a certain stage of differentiation in the course of neoplastic process. Later, Chu and Arber [36] showed positive cytoplasmic staining in 13 of $24(54 \%)$ urothelial carcinomas, while there was no reaction in non-neoplastic tissues. However, they did not investigate any correlation of low and high grade or stage with CD 10 expression. These results suggest that neoplastic tissues rather than non-neoplastic epithelium have a propensity for CD 10 expression. Murali and Delprado [37] demonstrated CD 10 expression in $80 \%$ of invasive carcinomas and also proved that the staining intensity for the high grade group (including invasive carcinoma, high-grade papillary urothelial carcinoma, and carcinoma in situ) was statistically higher than that of the low-grade group (including low-grade papillary urothelial carcinoma, papillary urothelial neoplasm of low malignant potential and normal urothelium).

In another study by Bircan et al., [35], they demonstrated CD10 staining in 34 of $79(43 \%)$ urothelial carcinomas including only one case of non-neoplastic epithelium. They found an inverse correlation between CD10 expression and tumor stage, but no association with histologic grade or staining score was detected. The authors proposed that the higher level of CD10 expression in noninvasive carcinomas appears to inhibit cell invasion.

Abdou [38] demonstrated CD10 expression in urothelial carcinoma and its correlation with parameters like advanced stage, tumor size, and shorter mean survival but not with grade. The authors suggested that CD 10 appears to be associated with tumor progression and that it could play a pivotal role in bladder cancer pathogenesis.

Bahadir et al., [13] assessed CD10 expression in urothelial carcinoma in urinary bladder and indicated strong correlation with high grade and stage of tumor and its association with tumor progression in bladder cancer pathogenesis.

Such discrepancies can be explained by difference in sample size, moreover, improper staging of the specimens due to subjective errors in assessing the stage or improper transurethral resection technique in which deeper tissues especially the muscular layer had not been taken, may contribute to under or over estimation of staging in these cases which in turn affects the number of cases in 
each stage. CD10 immunohistochemical marker had used a different scoring method, such variations in scoring systems will definitely affect the number of positive cases and affecting the correlation significance.

In agreement with Mohamed et al., [39], CD 10 did not show any association with patient gender or age. As regard bilharzial cystitis our results are similar to those of Abdou [38] who found that presence or absence of bilharziasis made no statistically significant difference regarding CD 10 expression.

\section{Conclusion:}

This study revealed that HER2-neu and CD 10 expression was directly related to grade and stage of tumor and may be associated with tumor progression in bladder cancer pathogenesis. Therefore, HER 2 and CD10 expression could be of valuable significance in the differentiation between high and low-grade urothelial carcinoma of urinary bladder and in determining the prognosis in such cases.

\section{References}

1- PLOEG M., ABEN K.K. and KIEMENEY L.A.: The present and future burden of urinary bladder cancer in the world. World J. Urol., 27: 289, 2009.

2- EDWARDS B.K., WARD E., KOHLER B.A., et al.: Annual report to the nation on the status of cancer, 19752006, featuring colorectal cancer trends and impact of interventions (risk factors, screening, and treatment) to reduce future rates. Cancer, 116 (3): 544-573, 2010.

3- SIEGEL R., MA J., ZOU Z. and JEMAL A.: Cancer statistics, 2014. CA Cancer J. Clin, 64: 9-29, 2014.

4- HOLMÄNG S., HEDELIN H., ANDERSTRÖM C. and JOHANSSON S.L.: The relationship among multiple recurrences, progression and prognosis of patients with stages Ta and T1 transitional cell cancer of the bladder followed for at least 20 years. J. Urol., 153: 1823-6; discussion: 1826-7, 1995.

5- GRIVAS P.D., DAY M. and HUSSAIN M.: Urothelial carcinomas: A focus on human epidermal receptors signaling. Am. J. Transl. Res., 3 (4): 362-373, 2011.

6- MERIC-BERNSTAM F. and HUNG M.C.: Advances in targeting human epidermal growth factor receptor-2 signaling for cancer therapy. Clin. Cancer Res., 12: 63266330, 2006.

7- YARDEN Y.: The EGFR family and its ligands in human cancer: Signaling mechanisms and therapeutic opportunities. Eur. J. Cancer, 37 (4): S3-S8, 2001.

8- HUDIS C.A.: Trastuzumab: Mechanism of action and use in clinical practice. N. Engl. J. Med., 357: 39-51, 2007.

9- YAMADA Y., NARUSE K., NAKAMURA K., et al.: Potential for molecular-targeted therapy targeting human epidermal growth factor receptor-2 for invasive bladder cancer. Oncol. Rep., 18 (1): 3-7, 2007.
10- KRUGER S., LANGE I., KAUSCH I., et al.: Protein expression and gene copy number analysis of topoisomerase 2 alpha, HER 2 and p53 in minimally invasive urothelial carcinoma of the urinary bladder: A multi-tissue array study with prognostic implications. Anticancer Res., 263271, 2005.

11- KRUGER S., WEITSCH G., BUTTNER H., et al.: HER2 overexpression in muscle-invasive urothelial carcinoma of the bladder: Prognostic implications. Int. J. Cancer, 102: 514-518, 2002.

12- GANDOUR-EDWARDS R., LARA P.N., FOLKINS A.K., et al.: Does HER2/Neu expression provide prognostic information in patients with advanced urothelial carcinoma? Cancer, 95 (5): 1009-1015, 2002.

13- BAHADIR B., BEHZATOGLU K., BEKTAS S., BOZKURT E.R. and OZDAMAR S.O.: CD10 expression in urothelial carcinoma of the bladder. Diagn. Pathol., 4: 38, 2009.

14- IWAYA K., OGAWA H., IZUMI M., KURODA M. and MUKAI K.: Stromal expression of CD10 in invasive breast carcinoma: A new predictor of clinical outcome. Virchows Arch., 440: 589-93, 2002.

15- BROWN G., HOGG N. and GREAVES M.: Candidate leukaemia-specific antigen in man. Nature, 258: 454-6, 1975.

16- MORABITO F., MANGIOLA M., RAPEZZI D., ZUPO S., OLIVA B.M., FERRARIS A.M., et al.: Expression of CD10 by B-chronic lymphocytic leukaemia cells undergoing apoptosis in vivo and in vitro. Haematologica., 88: 864-73, 2003

17- MOCH H., HUMPHREY P.A., ULBRIGHT T.M., REUTER V.E., eds.: WHO Classification of Tumours of the Urinary System and Male Genital Organs. 4 th ed. Lyon, France: IARC Press; World Health organization Classification of Tumours, Vol. 8, 2016.

18- SHAWKY A.E., ABDELHAFEZ A., ELOSAILY G.M., AL-MATUBSI H.Y. and FARAHAT A.: (Her-2/Neu Overexpression in Invasive Bladder Carcinoma Among a Cohort of Egyptian Patients. World J. Nephrol. Uro., 2 (2): 70-75, 2013

19- ATIQUE M., ABBASI M.S., JAMAL S., KHADIM M.T., AKHTAR F. and JAMAL N.: CD 10 expression intensity in various grades and stages of urothelial carcinoma of urinary bladder. J. Coll. Physicians Surg. Pak., 24 (5): 351-355, 2014.

20- JIMENEZ R.E., HUSSAIN M., BIANCO F.J., et al.: Her$2 /$ neu overexpression in muscle-invasive urothelial carcinoma of the bladder: Prognostic significance and comparative analysis in primary and metastatic tumors. Clin. Cancer Res., 7 (8): 2440-2447, 2001.

21- COOGAN C.L., ESTRADA C.R., KAPUR S., et al.: HER-2/Neu protein overexpression and gene amplification in human transitional cell carcinoma of the bladder. Urol. J., 63: 786-790, 2004.

22- ATIS G., ARISAN S. and DALKILINC A.: Determination of Her-2/Neu gene amplification and protein overexpression in bladder transitional cell carcinoma. Adv. Mol. Biol., 1: 89-94, 2007.

23- SKAGIAS L., POLITI E., KARAMERIS A., SAMBAZIOTIS D., ARCHONDAKIS A., VASOU O., NTINIS A., 
MICHALOPOULOU F., MOREAS I., KOUTSELINI H., et al.: Prognostic impact of HER2/neu protein in urothelial bladder cancer. Survival analysis of 80 cases and an overview of almost 20 years' research. J. BUON, 14: 457$462,2009$.

24- ENACHE M., SIMIONESCU C.E. and STEPAN A.: EGFR and Her2/neuimmunoexpression in papillary urothelial bladder carcinomas. Rom J. Morphol. Embryol., 54 (1): 137-141, 2013.

25- ABD EL-FATTAH G.A., EL-SAWI R.M. and ABD RABUH R.M.: Prognostic Value of CD44 and HER2/Neu in Invasive Transitional Cell Carcinoma of the Urinary Bladder. Med. J. Cairo Univ., 82 (2): 81-87, 2014.

26- ALEXA A., BADERCA F., ZAHOI D.E., LIGHEZAN R., IZVERNARIU D. and RAICA M.: Clinical significance of Her2/neu overexpression in urothelial carcinomas. Rom. J. Morphol. Embryol., 51 (2): 277-282, 2010.

27- IOACHIM E., CHARCHANTI A., STAVROPOULOS N.E., SKOPELITOU A., ATHANASSIOU E.D. and AGNANTIS N.J.: Immunohistochemical expression of retinoblastoma gene product $(\mathrm{Rb}), \mathrm{p} 53$ protein, MDM2, cerbB-2, HLA-DR and proliferation indices in human urinary bladder carcinoma. Histol. Histopathol., 15: 721727, 2000.

28- KORKOLOPOULOU P., CHRISTODOULOU P., KAPRALOS P., EXARCHAKOS M., BISBIROULA A., HADJIYANNAKIS M. and GEORGOUNTZOS C.: The role of p53, MDM2 and c-erb B-2 oncop-roteins, epidermal growth factor receptor and proliferation markers in the prognosis of urinary bladder cancer. Pathol. Res. Pract., 193 (11-12): 767-775, 1997.

29- VOLLMER R.T., HUMPHREY P.A., SWANSON P.E., WICK M.R. and HUDSON M.L.: Invasion of the bladder by transitional cell carcinoma: Its relation to histologic grade and expression of p53, MIB-1, c-erb B-2, epidermal growth factor receptor, and bcl-2. Cancer, 82 (4): 715723, 1998.

30- EL GEHANI K., AL-KIKHIA L., EMAETIG F., SYRJANEN K., AL-FITURI O. and ELZAGHEID A.: Over- expression of HER-2 is associated with the stage in carcinomas of the urinary bladder. Libyan J. Med., 7: 14964: 1-6, 2012.

31- EIS SA S., ALI H.S., AL TONSI A.H., et al.: HER2/neu expression in bladder cancer: Relationship to cell cycle kinetics. Clin. Biochem., 38 (2): 142-148, 2005.

32- KANDEMIR N.O., BAHADIR B., GUN B.D., YURDAKAN G., KARADAYI N. and ÖZDAMAR S .O.: CD10 expression in urothelial bladder carcinomas: Staining patterns and relationship with pathologic parameters. Turk. J. Med. Sci., 40: 177-184, 2010.

33- MOHAMMAD A.S., ALI H.H., QASIM B.J. and CHALOOB M.K.: CD10 and CA19.9 immunohistochemical expression in transitional cell carcinoma of the urinary bladder. Urol. Ann. J., 5 (2): 81-85, 2013.

34- KOISO K., AKAZA H., OHTANI M., MIYANAGA N. and AOYAGI K.: A new tumor marker for bladder cancer. Int. J. Urol., 1: 33-36, 1994.

35- BIRCAN S., CANDIR O., KAPUCUOGLU N., SEREL T.A., SEREL T.A., CIRIS M., KARAHAN N., CIRIS M. and KARAHAN N. CD 10 expression in urothelial bladder carcinomas: A pilot study. Urol. Int., 77: 107-113, 2006.

36- CHU P. and ARBER D.A.: Paraffin-section detection of CD10 in 505 non-hematopoietic neoplasms. Frequent expression in renal cell carcinoma and endometrial stromal sarcoma. J. Clin. Pathol., 113: 374-82, 2000.

37- MURALI R. and DELPRADO W.: CD10 immunohistochemical staining in urothelial neoplasms. Am. J. Clin. Pathol., 124: 371-9, 2005.

38- ABDOU A.G.: CD10 expression in tumour and stromal cells of bladder carcinoma: An association with bilharziasis. APMIS, 115: 1206-1218, 2007.

39- MOHAMED A., RAMADAN M., HELMY O. and MOHAMED S.: Immunohistochemical expression of CD10 and HER-2/NEU in urothelial carcinoma versus chronic cystitis in Zagazig University Hospitals (retrospective study). Zagazig University Medical Journal, 23: 1-8. 10.21608/zumj.2017.4683, 2017. 


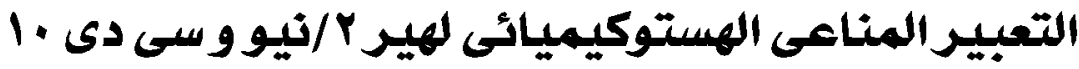 في سرطان المثانة البولية البية}

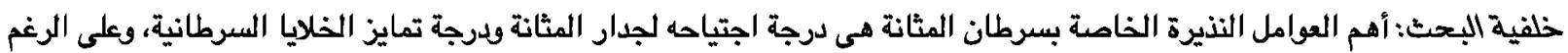

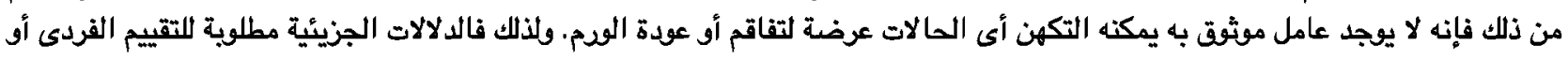

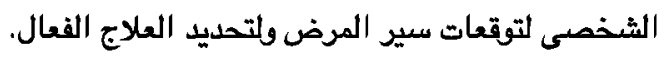

الهدف من البحث: الهدف من هذه الدراسة هو تقييم التعبير المناعى لكل من (هير ك/نيو) و (سى دى ـ إ) وتحديد العلاقة بينهم وبين

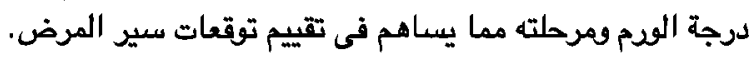

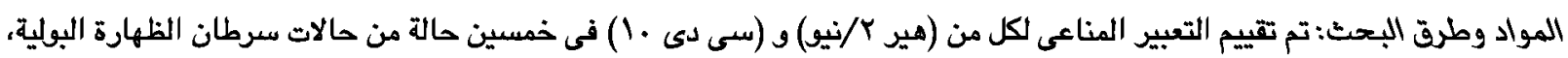

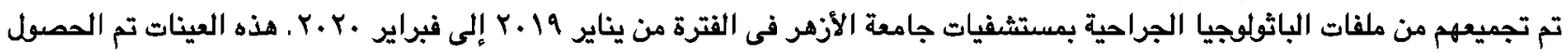

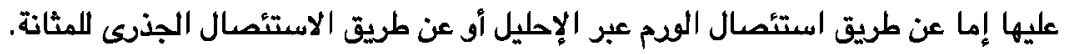

نتائج البحث: كان هنالك فارق ذو دلالة إحصائية بين التعبير المناعى لكل من (هير كارينيو) و (سى دى ـ ـ1) فى سرطان الظهارة البولية

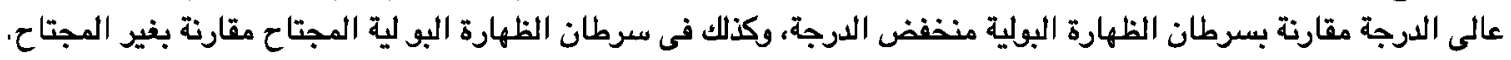

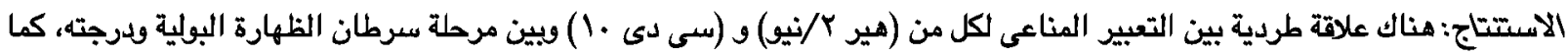

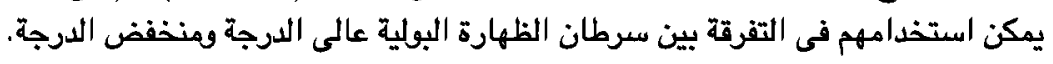

